\title{
UN MARCO COMÚN DESDE LA TOPONIMIA A LA ENERGÍA SOLAR
}

\author{
XAVIER PONS \\ Grumets research group. \\ Dep. de Geografia, Edifici B, Universitat Autònoma de Barcelona, Cataluña, España \\ xavier.pons@uab.cat
}

En el presente número 18 de GeoFocus, el segundo de 2016, se nos presentan 10 trabajos en que la Ciencia y la Tecnología de la Información Geográfica hace aportaciones en áreas tan diversas como la evaluación multicriterio (Belenguer; Domínguez-Walle, Vargas-Tristán, Pérez, Niño-Maldonado, Treviño-Carreón, Herrera), toponimia [gracias a una de las muchísimas aplicaciones que tiene esta relativamente reciente -al menos en su uso generalizado- forma de teledetección que es el lidar] (Membrado), gestión territorial (Lanceta, Entraigas, de Dominicis, Vercelli), fusión de imágenes de teledetección (Borini, Montorio, Pérez-Cabello, Vlassova), prospectiva (Naranjo, Gutiérrez, Ruíz, Cuadrado), riesgos biológicos (Manzano, Folgueiras, Germinal, Prieto), gestión de recursos públicos (Nieto, Cárdenas), recursos renovables (Martín, Domínguez, Amador) o accesibilidad viaria (López-Escolano, Pueyo, Postigo, Alonso).

Esperamos que estos trabajos, que enriquecen nuestra comunidad científica, resulten de vuestro interés en línea con la ilusión con que Autores y Editores los ponemos al alcance de cualquier persona gracias a la política de Acceso Abierto de GeoFocus.

Me complace asimismo anunciar que estamos en avanzado proceso para dotar a los artículos de DOI, lo cual repercutirá en una mejor catalogación y difusión de la investigación de la que GeoFocus es depositaria.

Como siempre, agradezco a los Autores su aportación de originales, y a todo el Equipo Editorial su intensa labor. Gracias a todos ellos tenemos disponible un nuevo número de la revista. 
